\title{
Проблемы соблюдения речевого этикета в интернет-коммуникациях
}

\author{
Шаховалова Е.Г., Шаховалов Н.Н. \\ Алтайский государственный институт культуры, \\ Россия, 656055, г. Барнаул, ул. Юрина, 277 \\ E-mails: snn_1979@mail.ru, esh1001@mail.ru
}

\begin{abstract}
Аннотация. Соблюдение речевого этикета в виртуальном общении - проблема современного общества. Культура составления электронных текстов в процессе переписки, правила вежливости и доброжелательности не соблюдаются большинством пользователей, нормативно-правовая база, регламентирующая деятельность сайтов социальных сетей, отсутствует. Вопрос чистоты русского языка, речевой культуры - ключевая экологическая проблема в области языкознания. Вместе с тем проблема соблюдения речевого этикета в интернет-коммуникациях обучающимися высшей школы разработана недостаточно. В связи с этим авторами в целях выявления позиции участников виртуального общения к проблеме соблюдения речевого этикета в сети Интернет и их готовности к решению данного вопроса было проведено микроисследование среди обучающихся высшей школы. Даны характеристики основных форм и жанров интернет-коммуникаций, рассмотрены понятия «речевой этикет», «сетевой этикет», обоснована необходимость соблюдения речевого этикета в интернет-общении. Введение в интернет-пространство единых правил и норм вежливости позволит участникам виртуального общения сохранить экологию слова, традиции русского национального речевого этикета, как следствие, не разрушить самосознание и идентичность. Авторы также излагают аспекты соблюдения речевого этикета в сети Интернет.
\end{abstract}

Ключевые слова: этикет, сетевой этикет, виртуальное общение, социальные сети, электронный диалог.

Для цитирования: Шаховалова Е.Г., Шаховалов Н.Н., 2020. Проблемы соблюдения речевого этикета в интернет-коммуникациях. Вопросы журналистики, педагогики и языкознания, 39 (3): 455-465. DOI 10.18413/2712-7451-2020-39-3-455-465

\section{Problems with speech etiquette in Internet communications}

\author{
Elena G. Shakhovalova, Nikolai N. Shakhovalov \\ Altai State Institute of Culture, \\ 277 Yourina St, Barnaul, 656055, Russia \\ E-mails: snn_1979@mail.ru, esh1001@mail.ru
}

\begin{abstract}
Compliance with speech etiquette in virtual communication is a problem of modern society. The culture of writing electronic texts in the course of correspondence, the rules of politeness and goodwill are not observed by most users, and there is no legal framework regulating the activities of social network sites. The issue of the purity of the Russian language and speech culture is a key environmental problem in the field of linguistics. However, the problem of compliance with speech etiquette in Internet communications by students of higher education is not sufficiently developed. In this regard, in order to identify the position of participants in virtual communication to the problem of compliance with speech etiquette on the Internet and their readiness to solve this issue, the authors conducted a micro-study among students of higher education. The characteristics of the main forms and genres of Internet communications are given, the concepts of "speech etiquette" and "network etiquette" are considered, and the need to observe speech etiquette in Internet communication is justified. The introduction of common rules and norms of politeness in the Internet space will allow participants of
\end{abstract}


virtual communication to preserve the ecology of the word, the traditions of Russian national speech etiquette, and as a result, not to destroy self-consciousness and identity. The authors also describe aspects of speech etiquette in the Internet.

Keywords: etiquette, network etiquette, virtual communication, social networks, electronic dialogue.

For citation: Shakhovalova E. G., Shakhovalov N. N., 2020. Problems with speech etiquette in Internet communications. Issues in Journalism, Education, Linguistics, 39 (3): 455-465 (in Russian). DOI 10.18413/2712-7451-2020-39-3-455-465

\section{Введение}

Современная эпоха отличается стремительным и динамичным развитием цифровых и компьютерных технологий. Научный прорыв в информационных технологиях обусловил появление такого феномена как всемирная сеть Интернет. Все больше Интернет выполняет роль канала коммуникации, становится особой средой общения, что приводит к развитию новых социокультурных процессов, обусловливает возникновение инновационных типов коммуникаций [Морозова, 2010]. Интернет-коммуникация представляет собой способ общения, при котором передача информации и обмен данными осуществляется по каналам связи Интернета с использованием стандартных записей [Шаховалов, Шаховалова, 2019].

В последнее время учеными в сфере информационных технологий активно используется понятие «компьютерно-опосредованная коммуникация» [Розина, 2002], где сохраняется формальная близость к оригинальному термину (computer-mediated communication) и передаются базовые для понимания значения термина понятия (компьютер, среда, коммуникация). Так, исследователи вычленяют следующие «компоненты компьютерноопосредованной коммуникации: взаимодействие пользователя с пользователем, мобильная телефония, текстовая основа общения» [Intermedia..., 1986; Herring, 2007].

Основанием для классификации видов электронной связи являются различные параметры. Исследователи определяют следующие характеристики: «синхронная / асинхронная связь; официальный / неофициальный характер коммуникации; спонтанность / подготовленность речи; коммуникативные намерения участников и тематическая направленность речевого поведения; коммуникации с одним или многими пользователями; общение, базирующееся на технологиях Веб 1.0 или Веб 2.0» [Розина, 2002; Савилова и др., 2015].

Коммуникативные технологии различаются по времени и месту нахождения участников интернет общения:

Chat, IRC);

- одно время и одно виртуальное местонахождение - чаты (Internet relay,

- одно время, но различное местонахождение - ICQ, интернет-телефония, аудиоили видеоконференцсвязь;

- разное время, но одно виртуальное местонахождение - веб-форумы, гостевые книги;

- отличное время и разное местонахождение - электронная почта, списки рассылки, телеконференции.

Согласно описанным выше характеристикам выделяют виды электронной связи, основанные на службах традиционного Интернета, среди которых электронная почта, модерируемые списки рассылки, веб-форумы, чаты, видеоконференции, и базирующиеся на новейших технологиях Веб 2.0 веблоги, микроблоги, Skype, wiki, NetMeeting [Трепак, 2011].

В настоящее время в молодежной среде наиболее актуализировано интернетобщение в социальных сетях: «ВКонтакте», «Одноклассники», «Инстаграм», «Фейсбук», где наиболее востребовано общение в форумах и чатах. Форум является востребованным 
видом интернет-общения, где коммуникация осуществляется в режиме offline, а свои сообщения, которые сохраняются достаточно долго, участники коммуникации могут отсылать в разное время. Каждый новый участник знакомится с материалами форума и обозначает свою позицию.

«Чат» в прямом переводе с английского означает «дружеская беседа», «болтовня». Этот вид интернет-коммуникации представляет собой общение в режиме online [Колокольцева, 2016].

Содержание переписки в электронных диалогах при обсуждении каких-либо тем в рамках форумов, комментариев к фото, установленных статусов участников электронного общения открыты, как правило, для всех незаблокированных пользователей социальной сети. В большинстве случаев в диалогах собеседников используются ненормативная лексика, сленговые выражения, жаргонизмы, неуместные и неоправданные сокращения слов, допускаются орфографические и грамматические ошибки, в редких случаях участники диалога вежливы по отношению друг к другу, используют этикетные формулы речевого общения.

Анализ нормативно-правовой базы о функционировании официальных сайтов организаций, с одной стороны, свидетельствует о наличии нормативной документации, регламентирующей требования к структуре и контенту официального сайта, в частности, речь идет о сайтах образовательных организаций. Таким образом, ведение сайта в сфере образования обусловливает соблюдение норм этики и культуры общения в виртуальной среде $^{1}$. С другой стороны, анализ форумов и чатов в социальных сетях свидетельствует о нарушении этических норм и русского национального речевого этикета. В некоторых чатах функцию контроля за содержанием переписки осуществляют администраторы, которые отслеживают, не допускаются ли нецензурные выражения, националистические высказывания, оскорбления личности и др.

Изучение различных источников позволило выявить относительно новое понятие «сетевой этикет (сетикет)». Сетевой этикет - система правил общения, поведения во Всемирной сети $^{2}$ [Губайловский, 2004]. Сетикет позволяет участникам виртуальной коммуникации комфортно и легко общаться. Сетевым этикетом называют раздел общественной этики, включающий общие принципы поведения, которых должны придерживаться пользователи.

Вместе с тем в большинстве случаев администраторы социальных сетей игнорируют нарушение норм и правил речевого поведения, речевого этикета, которые допускают пользо-

${ }^{1}$ Об информации, информационных технологиях и о защите информации. Федеральный закон от 27 июля 2006 г. № 149-Ф3 в действующей редакции. URL: http://docs.cntd.ru/document /901990051 (дата обращения: 29.05.2020);

О внесении изменений в пункт 3 Правил размещения на официальном сайте образовательной организации в информационно-телекоммуникационной сети «Интернет» и обновления информации об образовательной организации. Постановление Правительства Российской Федерации от 17 мая 2017 г. № 575. URL: https://legalacts.ru/doc/postanovlenie-pravitelstva-rf-ot-17052017-n-575o-vnesenii/ (дата обращения: 15.05.2020);

О внесении изменений в требования к структуре официального сайта образовательной организации в информационно-телекоммуникационной сети «Интернет» и формату представления на нем информации, утвержденные приказом Федеральной службы по надзору в сфере образования и науки от 29 мая 2014 г. № 785. Приказ Министерства образования и науки Российской Федерации от 27 нояб. 2017 г. № 1968. URL: http://docs.cntd.ru/document/564859708 (дата обращения: 15.05.2020).

${ }^{2}$ Губайловский В. 2004. WWW-обозрение Влалимира Губайловского. Новый мир, 3 : 203-207. 
ватели сети. Переписка в форумах, чатах, блогах ведется неформально, чаще всего без соблюдения этических норм и русского национального речевого этикета. «Речевой этикет - система социально-заданных и национально-специфичных языковых знаков и правил их употребления, принятых в данном обществе в данное время с целью осуществления речевого контакта между собеседниками и поддержания общения в эмоционально положительной тональности в соответствии с речевой ситуацией» [Балакай, 2002].

Рассматривая соблюдение речевого этикета в виртуальной среде, следует отметить, что данное понятие сопряжено с термином «этикет». Во всех странах следование этикету означает «соблюдение правил поведения, обеспечивающих поддержание принятых в данном обществе норм поведения человека» [Гришанова, 1998]. Вежливость предполагает доброжелательное отношение собеседников друг к другу. «Отсутствие вежливости свидетельствует о незнании или несоблюдении правил этикета. Высокий уровень вежливости уместен лишь в особых ситуациях общения, чрезмерная вежливость может вызвать раздражение адресата общения» [Зорина, 2011].

Коммуникативное пространство Интернета обусловливает выбор иных форм вежливости в электронном диалоге. Факторы, обусловливающие формирование интернетэтикета: 1) дистантный характер общения; 2) возраст коммуникантов; 3) установка на языковую игру [Борисенко, 2015; Голошубина, 2014].

Речь - это основная форма вербальной коммуникации. Письменная форма этики ограничена строгими рамками - стилистикой, правилами орфографии и пунктуации. Так как это - широкое понятие, нигде нет единого речевого этикета, идеально подходящего под все социальные требования. Конкретные люди или социальные группы видоизменяют правила под свои потребности, не изменяя главных принципов - так рождается классификация речевого этикета по видам: официальный или деловой. Деловой речевой этикет применяется на мероприятиях, где гости не знакомы друг с другом, на выставках, в сфере обслуживания, на деловых переговорах. Повседневный речевой этикет - наиболее простой для освоения и распространённый вид, соблюдение правил повседневного этикета не требует усилий, воспитанный и интегрированный в общество человек соблюдает большинство правил и норм речевого этикета в процессе общения автоматически. Повседневный этикет применим в любой ситуации, где не подходит официальный этикет или более редкие формы речевого этикета.

Вопрос чистоты русского языка, речевой культуры - ключевая экологическая проблема в области языкознания [Шаховалова, 2020]. Лингвисты, филологи, исследователи в области языкознания: Л.А. Введенская [2005], А.В. Кравченко [2005], В.С. Миловатский [2001], Л.И Скворцов [2009], А.П. Сковородников [1992] обеспокоены снижением норм речевой культуры: сегодня поднимается вопрос об экологии языка, экологии слова, экологии культуры речи. В последние годы наиболее актуализируется проблема соблюдения речевого этикета в интернет-коммуникациях. Так, в работе А.С. Борисенко [2015] рассматриваются аспекты соблюдения норм культуры речи в виртуальной среде, в публикациях О.К. Голошубиной [2014], П.В. Морослина [2009] освещаются вопросы о необходимости соблюдения речевого этикета в Интернете. Вместе с тем проблема соблюдения речевого этикета в интернет-коммуникациях обучающимися высшей школы разработана недостаточно. В связи с этим авторами в целях выявления позиции участников виртуального общения к проблеме соблюдения речевого этикета в сети Интернет и их готовности к решению данного вопроса было проведено микроисследование среди обучающихся высшей школы.

\section{Объекты и методы исследования}

Объект исследования - речевой этикет обучающихся образовательных организаций высшего образования. Для проведения исследования были использованы такие методы наблюдения, как анкетирования, интервью, метод экспертного опроса. Экс- 
пертный опрос проводился среди обучающихся Алтайского государственного института культуры (АГИК).

Микроисследование включало следующие задачи:

1) рассмотреть предпочитаемые формы коммуникации в сети Интернет; тернет;

2) определить отношение обучающихся к соблюдению речевого этикета в сети Ин-

3) провести анализ использования обучающимися этикетных формул в интернеткоммуникациях;

4) актуализировать вопрос о введении запретов в социальных сетях с целью соблюдения речевого этикета.

Исходя из задач исследования, диагностика проводилась дистанционно среди студентов 1-3 курсов обучающихся музыкального факультета, факультета художественного творчества, факультета социально-культурных и информационных технологий АГИК в апреле - мае 2020 года. Всего в констатирующем исследовании приняли участие 100 обучающихся.

\section{Результаты исследования и их обсуждение}

В результате опроса выяснилось, что 93 \% используют для общения сеть Интернет. Следовательно, всемирная паутина является альтернативной формой общения и все более прогрессирует, постепенно заменяя реальное общение.

При ответе на вопрос «Необходимо ли использование четких рамок речевого этикета в социальных сетях» $65 \%$ опрошенных ответили «да», $8 \%$ - «нет», а $26 \%$ - «не задумывались об этом» (рис. 1).

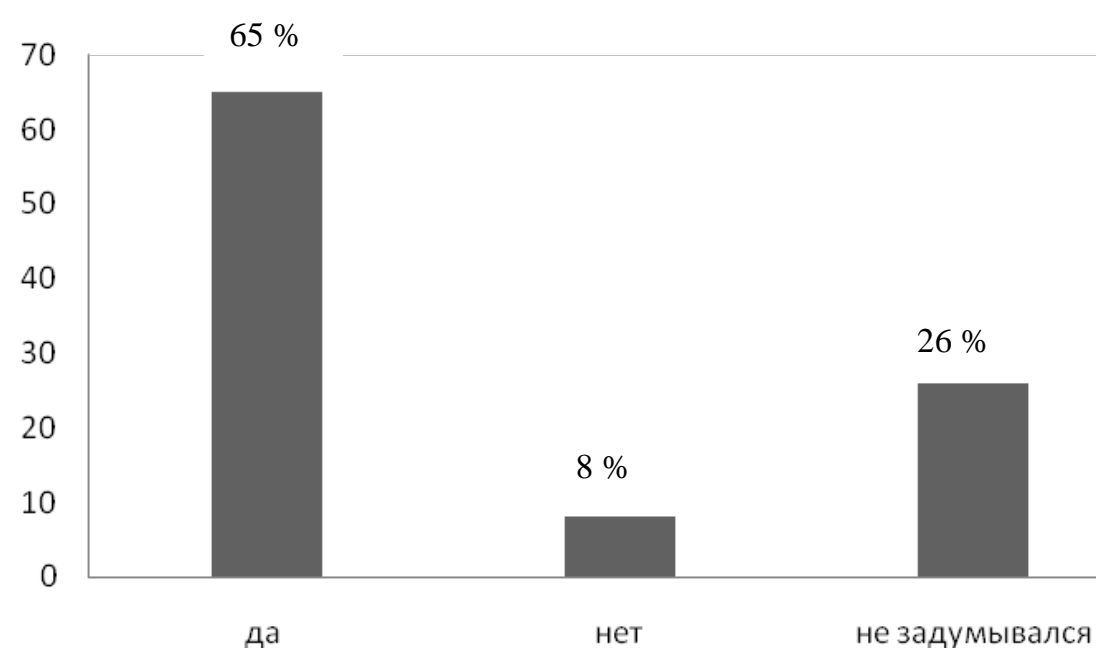

Рис. 1. Распределение мнений о необходимости придерживаться четких рамок речевого этикета в социальных сетях

Fig. 1. Distribution of opinions on the need to adhere to a clear framework speech etiquette in social networks

По ответам на вопрос: «Какие формы интернет-коммуникаций Bы используете чаще всего?» выяснилось (рис. 2), что практически все опрошенные - $96 \%$ - используют в интернет общении социальные сети, $75 \%$ - мессенджеры, электронную почту предпочитают использовать $37 \%$ опрошенных, чаты и телеконференции - 17 и 5 \% соответственно. Полученные данные свидетельствуют о популярности и востребованности у молодежи общения в социальных сетях и мессенджерах. 


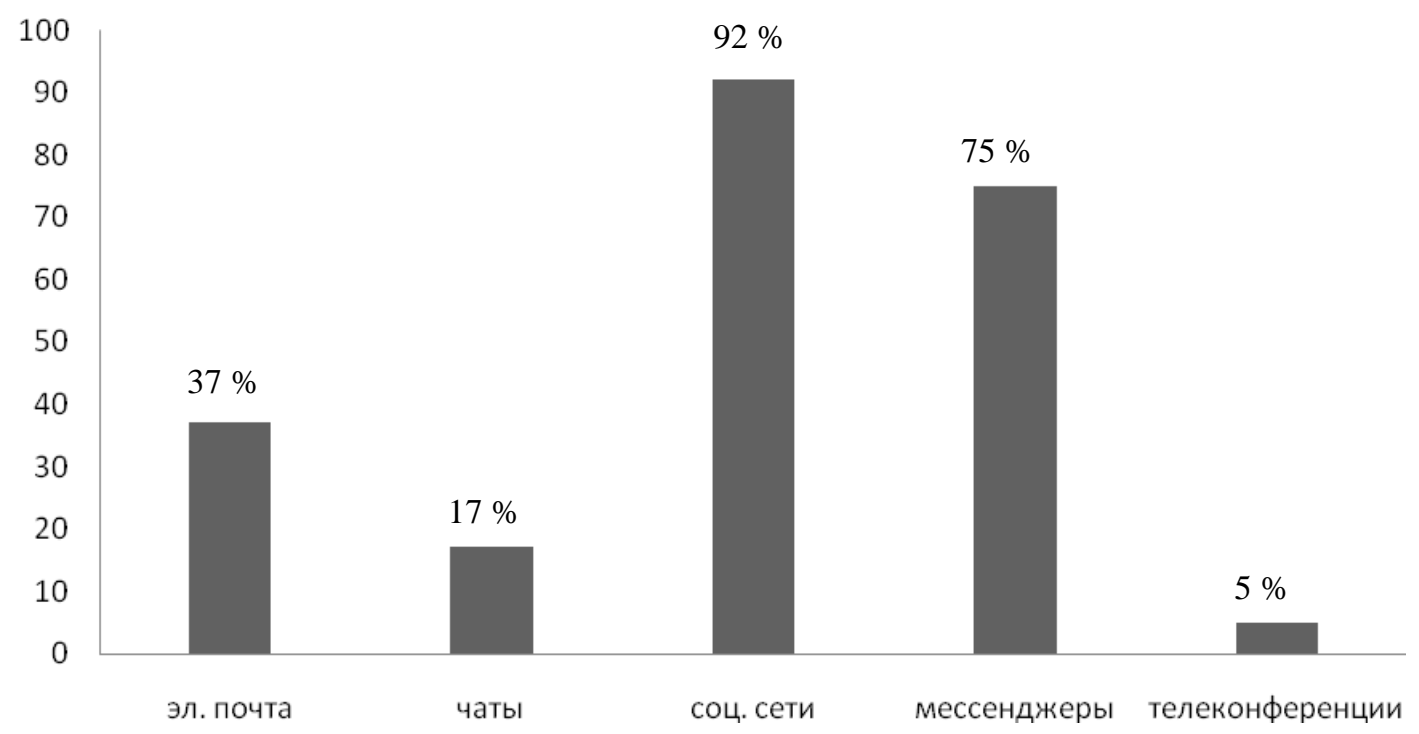

Рис. 2. Формы интернет-коммуникаций, используемые обучающимися

Fig. 2. Forms of Web Communication Used by Students

of Educational Institutions of Higher Education

Из всех социальных сетей наибольшее предпочтение опрошенные отдают социальным сетям: «ВКонтакте», «Инстаграм», наименьшее - «Одноклассники» и «Фейсбук» (рис 3).

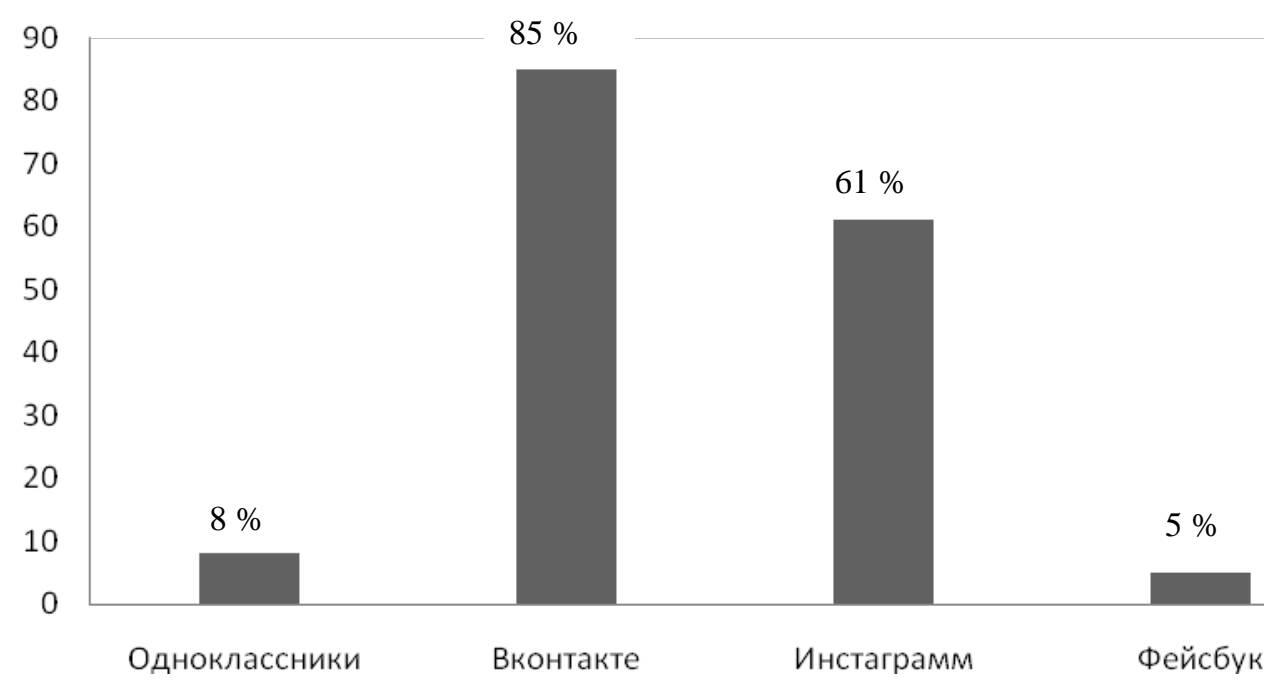

Рис. 3. Социальные сети, используемые обучающимися в интернет-общении

Fig. 3. Social Networking Websites that Are popular Among

Students of Educational Institutions of Higher Education

Далее респондентам предлагалось ответить на такой вопрос: «Необходимо ли придерживаться при общении в сочиальных сетях четких рамок речевого этикета?». В результате $65 \%$ опрошенных считают, что да - необходимо, $11 \%$ - нет необходимости, а 27 \% не задумывались над этим.

Понятие «интернет-этикет» известно $76 \%$ опрошенных, $9 \%$ - не знакомы с данным термином, 15 \% - затруднились с ответом. Результаты свидетельствуют об осознании 
большинством обучающихся ситуации искажения русского языка, русского речевого этикета, традиций русской национальной культуры в интернет-общении, где нарушается речевая культура, разрушается экология слова [Шаховалова, 2020].

При ответе на вопрос «Известны ли Вам нормы и правила речевого поведения, которые необходимо соблюдать в сети Интернет?» 65 \% опрошенных ответили «да», 13 \% - «нет», $21 \%$ - затруднились с выбором ответа (рис. 4).

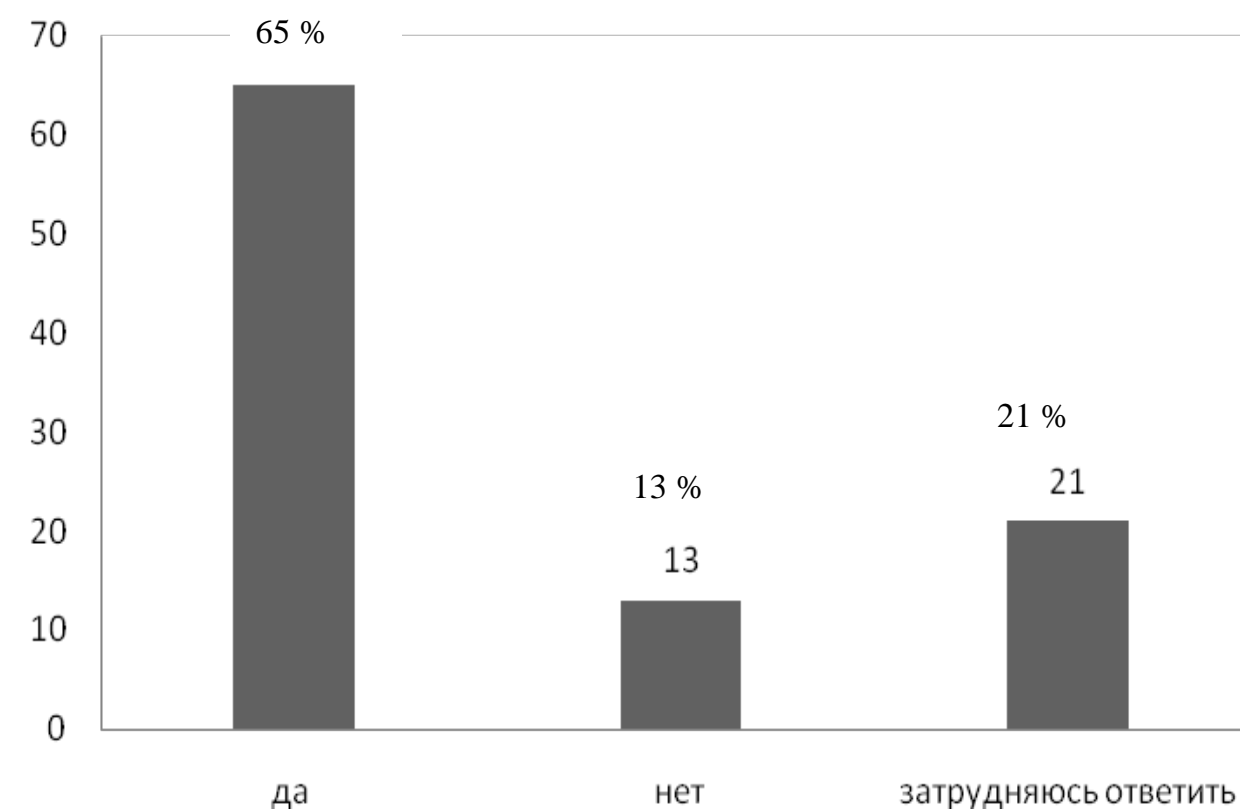

Рис. 4. Процентное распределения ответов на вопрос «Известны ли Вам нормы и правила речевого поведения, которые необходимо соблюдать в сети интернет?»

Fig. 4. Respondents' answers to a question «Do You Know Some Rules and Regulations of Speaking Etiquette that You Should Follow in Your Web Communication?»

Полученные данные свидетельствуют об оптимальном уровне сформированности общей речевой культуры большинства опрошенных, готовности использовать и соблюдать речевой этикет в любой ситуации, в виртуальном общении в частности, что демонстрируют ответы на вопрос: «Какие нормы речевого поведения вы соблюдаете в интернет-общении?». Процентное распределение представлено на рис. 5.

Представленные ответы демонстрируют различный спектр соблюдения речевого этикета в сети Интернет. Мнения опрошенных разделились, что свидетельствует об индивидуальном уровне сформированности базовой культуры личности, способности к рефлексии, позиционировании и проявлении бережного, экологичного отношения к слову.

В ходе экспертного опроса также было выявлено отношение обучающихся к введению запрета на нарушения речевого этикета в социальных сетях: 98 \% опрошенных выразили согласие запретить использование ненормативной лексики, обращение к собеседнику в неуважительной форме, воздержание от написания необходимых формул речевого этикета.

Результаты проведенного исследования обсуждались на Совете по науке АГИК, а также в рамках семинаров и практических занятий по дисциплинам «Русский язык и культура речи», «Этика делового общения», «Информационные технологии», «Интернеткоммуникации» в режиме онлайн. 


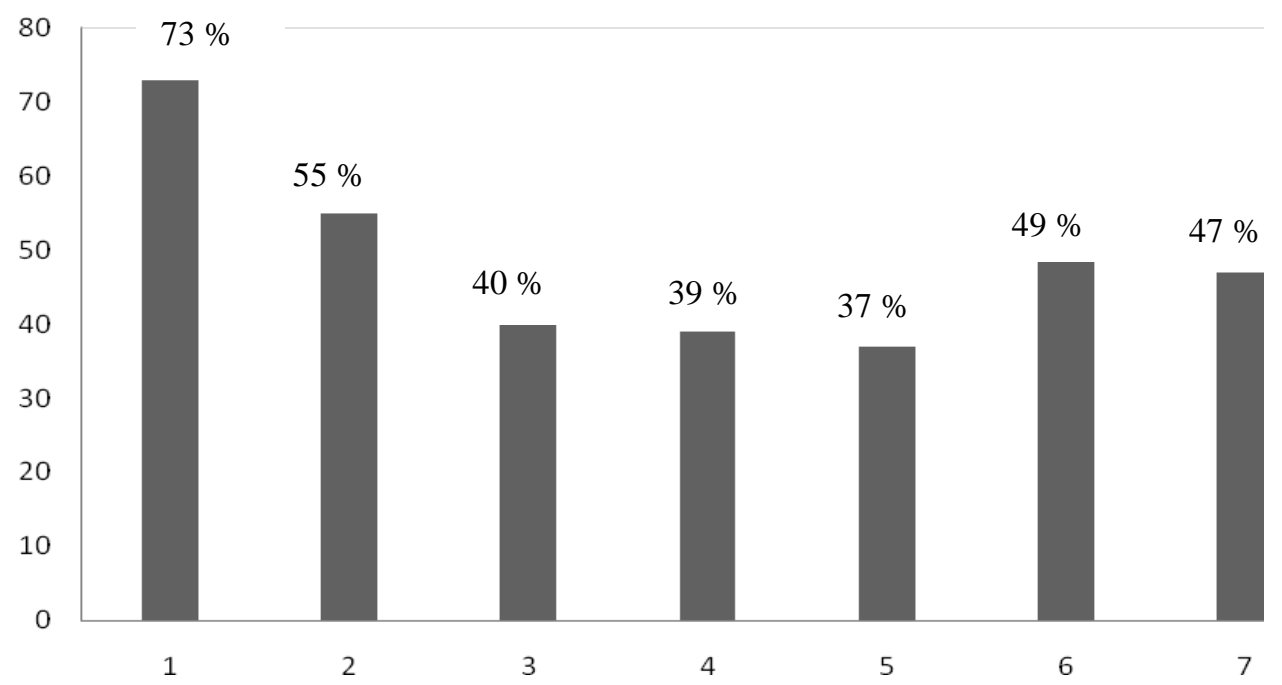

1 - Веду себя ненавязчиво, не выпрашиваю у друзей и подписчиков репосты и лайки.

2 - Всегда приветствую собеседника и обращаюсь к нему по имени.

3- Не использую в виртуальном общении ненормативную лексику.

4- Не использую сленг для сокращения переписки в деловой коммуникации и в общении на форумах, где сокращения могут быть непонятны для большинства собеседников. 5- Не злоупотребляю использованием смайликов и приемами усиления письменной речи (восклицательные, вопросительные знаки, заглавные буквы и др.), так как это воспринимается собеседниками как повышение тона.

6- Не затягиваю с ответом на сообщение и всегда говорю слова благодарности, после того, как мне ответили.

7 - Оспариваю мнение собеседника, не переходя на личности.

Рис. 5. Нормы речевого поведения, соблюдаемые обучающимися в интернет-общении

Fig. 5. Norms of speech behavior observed by students in Internet communication

\section{Заключение}

Из результатов проведенного микроисследования следует, что обучающиеся образовательных организаций высшего образования массово используют социальные сети, виртуальное общение прочно вошло в их повседневную жизнь. Однако вопрос о качестве общения в пространстве Интернета остается открытым. Все это негативно влияет на развитие языка, его сохранение для будущих поколений, поскольку язык, речь являются способом отражения самосознания народа, его идентичности.

Чтобы сохранить чистоту русского языка, нормы речевого поведения в виртуальной среде, по мнению авторов, необходимо соблюдать в любых ситуациях: от повседневного общения до обмена опытом на международных конференциях или дипломатических переговорах. Участникам диалогов необходимо уважительно относиться друг к другу, продумывать каждое сообщение, правильно оформлять текст, предполагается следование правилам культуры общения всеми участниками форумов, чатов, социальных сетей, пользователями электронной почты.

Наиболее распространенными ошибками речевого поведения являются следующие:

- использование неуместных выражений, сквернословие, употребление ненормативной лексики;

- нарушение ритуалов (не поздоровался, не поблагодарил, не извинился и пр.):

- присутствие в речи жаргонизмов («прикол», «лук», «улет» и т. д.);

- сарказм, приказной тон, грубость, невежество, отсутствие эмпатии по отношению к собеседнику; 
- упоминание о присутствующем человеке в третьем лице [Голошубина, 2014].

Законы вежливости в кибернетическом пространстве не должны отличаться от действующих правил в социуме. Придерживаться речевого этикета и пропагандировать необходимость следовать нормам в процессе коммуникации должны все пользователи Сети. Важно «выслушать» собеседников, избегать оскорблений и хамства, использовать слова вежливости: этикетные формулы приветствия («Здравствуйте», «Здравствуй», «Добрый день» и т.n.), прощания («Всего доброго», «До свидания», «До встречи»), благодарности («Благодарю», «Спасибо» с различными эмоциональными оттенками: «Cnaсибо большое», «Спасибо огромное» и др.). Вместе с тем данные правила, рекомендации не являются нормативными, регламентирующими как для участников электронного диалога, так и для администраторов (модераторов) сайтов социальных сетей, что негативно отражается на сохранении традиций исконно русского национального речевого этикета в современном обществе.

\section{Список литературы}

1. Балакай А.Г. 2002. Русский речевой этикет и принципы его лексикографического описания. Автореф. дис. ... докт. филол. наук. Орёл, 40 с.

2. Борисенко А.С. 2015. Культура речи в виртуальной среде. Современная наука: актуальные проблемы теории и практики. Серия Гуманитарные науки, 03-04: 51-53.

3. Введенская Л. А., Павлова Л.Г., Катаева Е.Ю. 2005. Русский язык и культура речи. Ростов н/Д, Феникс, 544.

4. Гришанова В.Н. 1998. Речевой этикет говора как элемент народной культуры. В кн.: Славянский альманах 1997. М.: Издательство «Индрик»: 307-312.

5. Голошубина О.К. 2014. Нормы речевого этикета в интернет-коммуникации (на примере речевого жанра «разговор в мессенджере»). Молодой учёный, 8 (67): 944-947.

6. Зорина Л.Ю. 2011. К проблемам изучения народного речевого этикета в вологодских говорах. Вестник Волгоградского государственного университета. Серия 2. Языкознание, 1 (13): $72-78$.

7. Колокольцева Т.Н. 2016. Диалогичность в жанрах интернет-коммуникации (чат, форум, блог). Жанры речи, 2 (14): 96-104.

8. Кравченко А.В. 2005. Бытие человека и экология языка. В кн.: Лингвистические парадигмы и лингводидактика. Материалы 10-й международной научно-практической конференции (Иркутск, 14-18 июня 2005 г.). Иркутск, ИГУ: 59-63.

9. Миловатский В.С. 2001. Об экологии слова. М., Просветитель, 176 с.

10. Морозова О.Н. 2010. Особенности Интернет-коммуникации: определение и свойства. Вестник Ленинградского государственного университета им. А.С. Пушкина, 5: 150-158.

11. Морослин П.В. 2009. Есть ли речевой этикет в Интернете? Русская речь, 4: 50-54.

12. Розина И.Н. 2002. Компьютерно-опосредованная коммуникация в педагогическом и научном взаимодействии. В кн.: Коммуникация: теория и практика в различных социальных контекстах (Коммуникация-2002). Материалы международной научно-практической конференции, г. Пятигорск, 03-06 июня 2002 года. Часть І. Пятигорск, Изд-во ПГЛУ: 138-145.

13. Савилова С.Л., Чан Т.3., Нгуен Т.А. 2015. Жанры интернет-коммуникации студенческого сообщества. Молодой ученый, 11 (91): 1679-1681.

14. Скворцов Л.И. 2009. Экология слова, или Поговорим о культуре русской речи. М., Просвещение, 208. $104-111$

15. Сковородников А.П. 1992. Об экологии русского языка. Филологические науки, 5-6:

16. Трепак Я.В. 2011. Теоретические аспекты компьютерно-опосредованной коммуникации. Вестник Московского университета. Серия 19. Лингвистика и межкультурная коммуникация, 4: 131-137.

17. Шаховалов Н.Н., Шаховалова Е.Г. 2019. Влияние интернет-коммуникаций на речевую культуру обучающихся образовательных организаций высшего образования. Научные ведомости Белгородского государственного университета. Гуманитарные науки, 38 (2): 336-344. 
18. Шаховалова Е.Г. 2020. Экология речевой культуры в современном социуме. В кн.: Формирование качественной культурной среды в малых городских и сельских поселениях. Материалы Всероссийской научно-практической конференции, г. Барнаул, 18-19 марта 2020 года. Барнаул, Изд-во АГИК: 65-72.

19. Шкапенко П.В. 2008. Специфика реализации прагмалингвистических принципов в интернет-дискурсе. Дис. ... канд. филол. наук. Калининград, 229 с.

20. Herring S.C. 2007. Faceted Classification Scheme for Computer-Mediated Discourse. Language@Internet. 4. Available at: https://www.semanticscholar.org/paper/A-Faceted-ClassificationScheme-for-Discourse-Herring/566a52afca7e06836d7d0acb5fec6268fe8f6b10 (accessed: 12.02.2020).

21. Intermedia: Interpersonal Communication in a Media World. 1986. Eds. G. Gumpert (itor), R. Cathcart. New York, Oxford University Press, 688 p.

\section{References}

1. Balakay A.G. 2002. Russkiy rechevoy etiket i printsipy ego leksikograficheskogo opisaniya [Russian speech etiquette and the principles of its lexicographic description]. Abstract. dis. ... doct. philol. sciences. Orel, $40 \mathrm{p}$.

2. Borisenko A.S. 2015. Kul'tura rechi v virtual'noy srede [Culture of speech in a virtual environment]. Modern Science: actual problems of theory and practice. Humanities series, 03-04: 51-53.

3. VvedenskayaL.A., Pavlova L.G., KataevaE.Yu. 2005. Russkij yazyk i kul'tura rechi [Russian language and speech culture]. Rostov-on-Don, $544 \mathrm{p}$.

4. Grishanova V.N. 1998. Rechevoy etiket govora kak element narodnoy kul'tury [Speech etiquette of dialect as an element of folk culture]. In: Slavic Almanac 1997. M., Publ. Indrik: 307-312.

5. Goloshubina O.K. 2014. Normy rechevogo etiketa v internet-kommunikatsii (na primere rechevogo zhanra «razgovor v messendzhere») [The norms of speech etiquette in Internet communication (on the example of the speech genre "conversation in the messenger")]. Molodoy uchenyy, 8 (67): 944-947.

6. Zorina L.Yu. 2011. K problemam izucheniya narodnogo rechevogo etiketa v vologodskikh govorakh [On the problems of studying folk speech etiquette in Vologda dialects]. Science Journal of Volgograd State University. Linguistics, 1 (13): 72-78.

7. Kolokol'tseva T.N. 2016. Dialogichnost' v zhanrakh internet-kommunikatsii (chat, forum, blog) [Dialogue in the genres of Internet communication (chat, forum, blog).]. Speech Genres, 2 (14): 96-104.

8. Kravchenko A.V. 2005. Existence and ecology of a language. In: Lingvisticheskie paradigmy i lingvodidaktika. Materialy 10-j mezhdunarodnoj nauchno-prakticheskoj konferencii (Irkutsk, 14-18 iyunya 2005 g.) [Linguistic paradigms and linguodidactics. Materials of International research-to-practice conference (Irkutsk, June 14-18, 2005)]. Irkutsk, Irkutsk State University Publishing House: 59-63 (in Russian).

9. MilovatskiV.S. 2001. Ob ekologii slova [On ecology of a word]. Moscow, Prosvetitel', 176 p. (in Russian).

10. Morozova O.N. 2010. Osobennosti Internet-kommunikatsii: opredelenieisvoystva [Features of Internet communication: definition and properties]. Vestnik of Pushkin Leningrad State University, 5: 150-158 (in Russian).

11. Moroslin P. V. 2009. Est li rechevoi etiket v internete [Is there Speech Etiquette on the Internet?] Russkaia rech [Spoken Russian], 4: 50-54 (in Russian).

12. Rozina I.N. 2002. Komp'yuterno-oposredovannaya kommunikatsiya v pedagogicheskom i nauchnom vzaimodeystvii [Computer-mediated communication in pedagogical and scientific interaction]. In: Kommunikatsiya: teoriya i praktika v razlichnykh sotsial'nykh kontekstakh (Kommunikatsiya-2002) [Communication: theory and practice in various social contexts (Communication-2002)]. Materials of the international scientific and practical conference, Pyatigorsk, June 03-06, 2002. Part I. Pyatigorsk, Publ. Izd-vo PGLU: 138-145.

13. Savilova S.L., Chan T.Z., Nguen T.A. 2015. Zhanry internet-kommunikatsii studencheskogo soobshchestva [Genres of Internet communication of the student community]. Molodoy uchenyy, 11 (91): 1679-1681.

14. Skvortsov L. I. 2009. Ekologiya slova, ili Pogovorim o kul'ture russkoj rechi [Ecology of a word: or, Let’s talk about Russian speech culture]. Moscow, Prosveshchenie, 208 p. (in Russian).

15. Scovorodnikov A.P. 1992. On ecology of Russian language. Philological sciences, 5-6: 104-111 (in Russian). 
16. Trepak Ya.V. 2011. Teoreticheskie aspekty komp'yuterno-oposredovannoy kommunikatsii [Theoretical aspects of computer-mediated communication]. Bulletin of Moscow University. Series 19. Linguistics and Intercultural Communication, 4: 131-137.

17. Shakhovalov N.N., Shakhovalova E.G. 2019. Vliyanie internet-kommunikatsiy na rechevuyu kul'turu obuchayushchikhsya obrazovatel'nykh organizatsiy vysshego obrazovaniya [The influence of Internet communications on the speech culture of students of educational institutions of higher education]. Belgorod State University Scientific Bulletin. Humanities series, 38 (2): 336-344.

18. Shakhovalova E.G. 2020. Ekologiya rechevoy kul'tury v sovremennom sotsiume [Ecology of speech culture in modern society]. In: Formirovanie kachestvennoy kul'turnoy sredy v malykh gorodskikh i sel'skikh poseleniyakh [Formation of a quality cultural environment in small urban and rural settlements]. Materialy Vserossiyskoy nauchno-prakticheskoy konferentsii, g. Barnaul, 18-19 marta 2020 goda. Barnaul, Publ. Izd-vo AGIK: 65-72.

19. Shkapenko P.V. 2008. Spetsifika realizatsii pragmalingvisticheskikh printsipov v internetdiskurse [The specifics of the implementation of pragmalinguistic principles in Internet discourse]. Dis. ... cand. philol. sciences. Kaliningrad, 229 p.

20. Herring S.C. 2007. Faceted Classification Scheme for Computer-Mediated Discourse. Language@Internet. 4. Available at: https://www.semanticscholar.org/paper/A-Faceted-ClassificationScheme-for-Discourse-Herring/566a52afca7e06836d7d0acb5fec6268fe8f6b10 (accessed: 12.02.2020).

21. Intermedia: Interpersonal Communication in a Media World. 1986. Eds. G. Gumpert (itor), R. Cathcart. New York, Oxford University Press, 688 p.

\section{ИНФОРМАЦИЯ ОБ АВТОРАХ}

Шаховалова Елена Геннадьевна, кандидат педагогических наук, заведующий отделом организации научно-исследовательской работы Алтайского государственного института культуры, г. Барнаул, Россия

Шаховалов Николай Николаевич, кандидат педагогических наук, доцент, доцент кафедры библиотековедения и информационных технологий Алтайского государственного института культуры, г. Барнаул, Россия

\section{INFORMATION ABOUT THE AUTHORS}

Elena G. Shakhovalova, Candidate of Pedagogical Sciences, Head of the Department for Organization of Research Work, Altai State Institute of Culture, Barnaul, Russia

Nikolai N. Shakhovalov, Candidate of Pedagogical Sciences, Associate Professor, Associate Professor of the Department of Library Science and Information Technologies, Altai State Institute of Culture, Barnaul, Russia 